\title{
Faustovirus-Like Asfarvirus in Hematophagous Biting Midges and Their Vertebrate Hosts
}

\section{OPEN ACCESS}

Edited by:

Gilbert Greub,

University of Lausanne, Switzerland

Reviewed by:

Vincent Thomas,

BIOASTER, France

Santhosh Chakkaramakkil Verghese, Oregon Health and Science University,

USA

*Correspondence:

Christelle Desnues

christelle.desnues@univ-amu.fr

Specialty section:

This article was submitted to

Virology,

a section of the journal

Frontiers in Microbiology

Received: 17 September 2015 Accepted: 25 November 2015 Published: 16 December 2015

Citation:

Temmam S, Monteil-Bouchard S,

Sambou M, Aubadie-Ladrix M,

Azza S, Decloquement P, Bou

Khalil JY, Baudoin J-P, Jardot $P$,

Robert C, La Scola B,

Mediannikov OY, Raoult $D$ and Desnues C (2015) Faustovirus-Like Asfarvirus in Hematophagous Biting Midges and Their Vertebrate Hosts.

Front. Microbiol. 6:1406.

doi: $10.3389 /$ fmicb.2015.01406

\begin{abstract}
Sarah Temmam ${ }^{1}$, Sonia Monteil-Bouchard ${ }^{1}$, Masse Sambou ${ }^{2}$, Maxence Aubadie-Ladrix ${ }^{2}$, Saïd Azza ${ }^{1}$, Philippe Decloquement ${ }^{1}$, Jacques Y. Bou Khalil ${ }^{1}$, Jean-Pierre Baudoin ${ }^{1}$, Priscilla Jardot ${ }^{1}$, Catherine Robert ${ }^{1}$, Bernard La Scola ${ }^{1,3}$, Oleg Y. Mediannikov ${ }^{1}$, Didier Raoult ${ }^{1,3}$ and Christelle Desnues ${ }^{1 *}$

1 Unité de Recherche sur les Maladies Infectieuses et Tropicales Emergentes, UM63 Centre National de la Recherche Scientifique 7278 IRD 198 Institut National de la Santé et de la Recherche Médicale U1095, Aix-Marseille Université, Marseille, France, ${ }^{2}$ Unité de Recherche sur les Maladies Infectieuses et Tropicales Emergentes, UM63 Centre National de la Recherche Scientifique 7278 IRD 198 Institut National de la Santé et de la Recherche Médicale U1095, Aix-Marseille Université, Dakar, Senegal, ${ }^{3}$ Fondation IHU Méditerranée Infection, Pôle des Maladies Infectieuses et Tropicales Clinique et Biologique, Fédération de Bactériologie-Hygiène-Virologie, Centre Hospitalo-Universitaire Timone, Méditerranée Infection, Assistance Publique - Hôpitaux de Marseille, Marseille, France
\end{abstract}

Faustovirus, a new Asfarviridae-related giant virus, was recently isolated in Vermamoeba vermiformis, a protist found in sewage water in various geographical locations and occasionally reported in human eye infection cases. As part of a global metagenomic analysis of viral communities existing in biting midges, we report here for the first time the identification and isolation of a Faustovirus-like virus in hematophagous arthropods and its detection in their animal hosts. The DNA virome analysis of three pools of Culicoides sp., engorged female Culicoides imicola and non-engorged male/female C. imicola biting midges collected in Senegal, revealed the presence of amoeba-infecting giant viruses and, among them, a majority of sequences related to Faustovirus. Phylogenetic analyses conducted on several structural genes of Faustovirus confirmed the clustering of the arthropod-borne Faustovirus with sewage-borne Faustoviruses, with a distinct geographical clustering of Senegalese Faustovirus strains. Transmission electron microscopy identified viral particles with morphologies and diameters which were compatible with Faustovirus. The presence of infectious arthropod-borne Faustovirus was finally confirmed by successful isolation on $V$. vermiformis amoeba. Global proteomic analysis of biting midges identified that arthropods' blood meal originating from cattle, rodents and humans. Further screening of cattle sera and rodent tissue resulted in prevalence of Faustovirus being estimated at 38\% in rodents and $14 \%$ in cattle, suggesting a possible origin of Faustovirus presence in arthropods via the ingestion of contaminated blood meal. Viral loads were the highest in rodents' urine and kidney samples, suggesting a possible excretion of viral particles into the environment. Faustovirus DNA polymerase-related sequences were also detected in more than 9 and $11 \%$ of febrile patients and healthy Senegalese human sera, respectively. Our study thus, highlights the need to investigate the role of arthropods, wildlife, and domestic animals in the lifecycle of amoeba-infecting giant viruses and, in particular, the environmental cycle of Faustovirus.

Keywords: biting midges, giant virus, faustovirus, bloodmeal host, environment 


\section{INTRODUCTION}

Large double-stranded (ds)DNA viruses, also known as "giant viruses," form a monophyletic group consisting of Poxviridae, Iridoviridae, Ascoviridae, Phycodnaviridae, Asfarviridae, Mimiviridae, and Marseilleviridae families and are classified under the proposed Megavirales order (Colson et al., 2012, 2013). More recently, discovery of Pandoravirus and Pithovirus genera has been reported (Philippe et al., 2013; Legendre et al., 2014).

Protozoans, and especially amoebas, have been largely used as tools to isolate and cultivate a wide variety of microorganisms, due to their lack of receptor-dependent infection and the ability of some bacteria and viruses to resist phagocytosis and to multiply in these organisms (Greub and Raoult, 2004). So far, giant viruses have been isolated on amoebae from various environments all over the world, mostly from water samples (Pagnier et al., 2013). Recently Faustovirus, a new virus closely related to the Asfarviridae family, has been isolated on Vermamoeba vermiformis protists in sewage water in various geographical locations (Reteno et al., 2015). Asfarviridae are a family of dsDNA viruses consisting of a unique member: the African swine fever virus (ASFV), the only known dsDNA virus transmitted by hematophagous arthropods, i.e., ticks.

Ceratopogonidae, and especially the genus Culicoides, are wellknown vectors of several parasites (Agbolade et al., 2006; Slama et al., 2014) and viruses (Mellor et al., 2000) infecting animals and human (i.e., Bluetongue virus, African Horse Sickness virus, Epizootic Hemorrhagic Disease virus, and Oropouche virus, the only known human virus transmitted by biting midges). In subSaharan countries such as Senegal, biting midges usually feed on livestock but also on humans. Larval stages of Culicoides sp. are found in semi-aquatic environments (Harrup et al., 2013), leading to possible contact with amoebae and their associated giant viruses.

In the present study, we report for the first time the detection, isolation, and environmental exploration of Faustovirus in adult Culicoides sp. biting midges.

\section{MATERIALS AND METHODS}

\section{Sample Collection and Ethical Statement Arthropods}

Biting midges were collected using a modified CDC light trap as previously described (Sambou et al., 2015), in the villages of Dielmo and Ndiop in the Sine-Saloum region of Senegal, in November 2013 (Figure 1). Traps were placed near places where cattle rested and were left overnight. Morphological identification of the arthropods was conducted the next morning, as previously described by Sambou et al. (2015). Three types of arthropod pools were created: the STE0043 pool consisted of more than 200 adult Culicoides sp., with no distinction between male and female, nor their gorged status; STE0044 and STE0045 pools consisted of 15 engorged female and 100 non-engorged male and female Culicoides imicola, respectively. Arthropods were immediately stored in liquid nitrogen directly in the field.
All these pools were collected from the same concession in Dielmo during the same night.

Hard ticks collected from cattle were harvested and directly stored in liquid nitrogen in pools according to their animal origin.

\section{Cattle}

Cattle sera were collected from animals at the same location as the CDC light traps used to sample biting midges. These were also immediately stored in liquid nitrogen.

\section{Rodents}

Rodent trapping was conducted at the same place: traps were left open overnight, and small mammals were sacrificed the next morning by cervical dislocation, according to the guidelines for the handling of wild mammals (Sikes and Gannon, 2011). All animal procedures carried out in this study were approved by the IRD Local Ethics Committee. The spleen, lungs, kidney, liver, brain, bladder, intestine, and serum were collected from trapped animals and directly stored individually in liquid nitrogen. Species identification of trapped small mammals was conducted by sequencing the $18 \mathrm{~S}$ rRNA, as previously described (Breitbart and Rohwer, 2005).

\section{Water}

Drinking water collected from wells in the two rural villages of Dielmo and Ndiop, and water collected from the Néma river in Dielmo were filtered through a $0.80-\mu \mathrm{m}$ filter, followed by a $0.45-\mu \mathrm{m}$ filter (Millipore, Molsheim, France). $10 \%$ (w/v) of PolyEthylenGlycol (PEG6000, Sigma Aldrich, Saint-Quentin Fallavier, France) and $300 \mathrm{mM} \mathrm{NaCl}$ (Sigma Aldrich, SaintQuentin Fallavier, France) were then added to precipitate viral particles and were incubated overnight at $+4^{\circ} \mathrm{C}$. After centrifugation at $12,000 \mathrm{~g}$ for $20 \mathrm{~min}$, the final pellet was resuspended in $2 \mathrm{~mL}$ of $0.02 \mu \mathrm{m}$-filtered PBS and stored in aliquots at $-80^{\circ} \mathrm{C}$.

\section{Human}

Human sera were collected through the Point-of-Care (POC) laboratory in Dielmo (Sokhna et al., 2013). One hundred and twelve sera from febrile people with no known etiology and 51 sera from healthy people were collected between November 2013 and June 2014. The National Ethics Committee of Senegal approved the most recent protocol, including the POC laboratory and activities, under the "Avis éthique et scientifique n ${ }^{\circ} 00081 \mathrm{du}$ 04 juin 2012."

\section{Sample Processing}

Fifty microliters of cattle sera, up to $20 \mu \mathrm{L}$ of rodent urine and $100 \mu \mathrm{L}$ of PEGylated water pellets were used to extract total nucleic acids using the High Pure Viral Nucleic Acids kit (Roche Diagnostics, Mannheim, Germany), according to the manufacturer's instructions.

Approximately $0.5 \mathrm{~cm}^{3}$ of rodent tissues and up to five hard ticks were crushed in pools with two 3-mm tungsten beads and a TissueLyser at $25 \mathrm{~Hz}$ for $2 \mathrm{~min}$ (Qiagen, Courtaboeuf, France) in $2 \mathrm{~mL}$ of sterile EMEM (Life Technologies, Saint Aubin, 


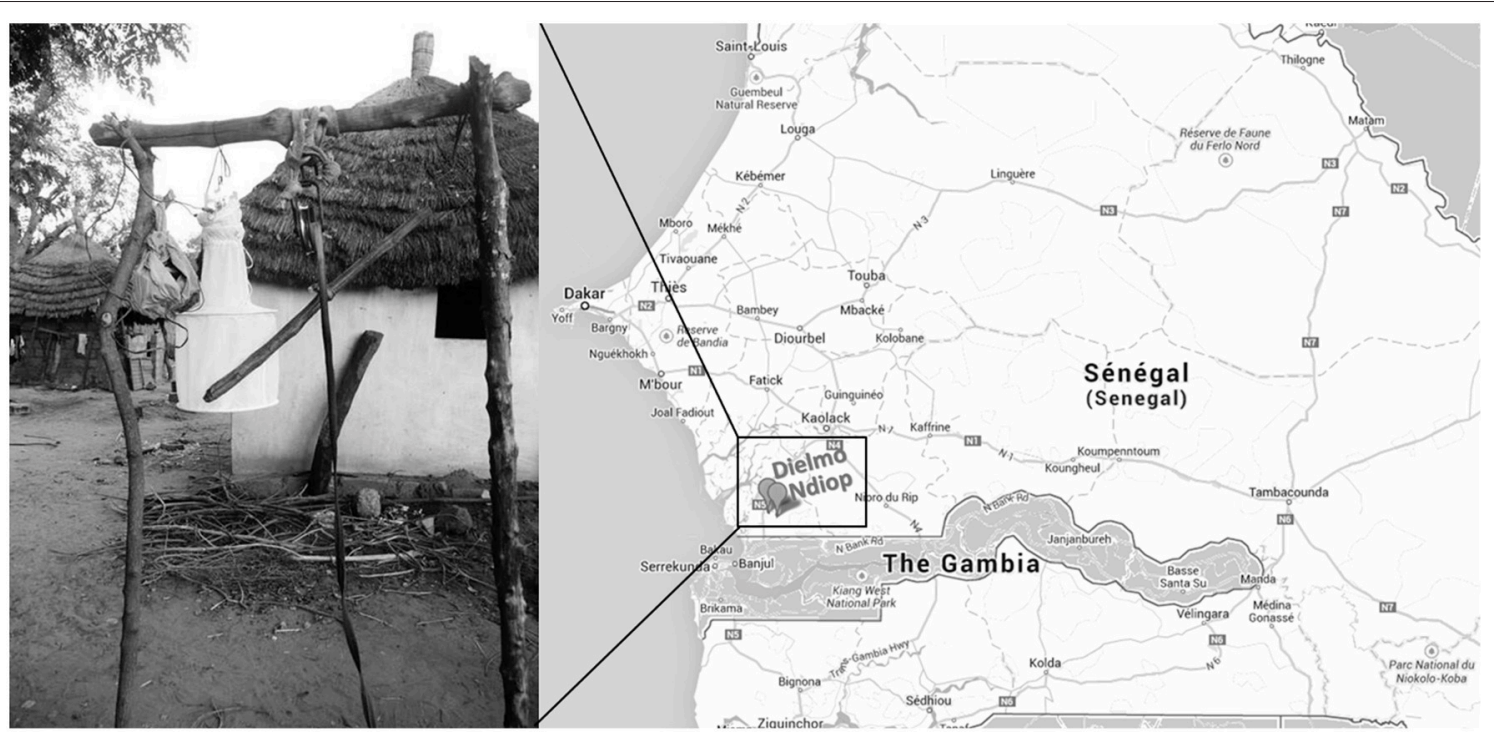

FIGURE 1 | Sampling sites.

France). Two hundred microliters of clarified supernatant was then processed for nucleic acid extraction as for cattle sera.

Total nucleic acids from human sera were previously extracted within the POC laboratory in Dielmo. Briefly, $200 \mu \mathrm{L}$ of human capillary blood was extracted using the Nucleospin Tissue kit (Macherey-Nagel, Hoerdt, France), according to the manufacturer's recommendations.

\section{Virome Preparation}

The three pools of arthropods were crushed with two 3$\mathrm{mm}$ tungsten beads and a TissueLyser at $25 \mathrm{~Hz}$ for $2 \mathrm{~min}$ (Qiagen, Courtaboeuf, France). The clarified supernatant was subsequently used as a template for virome preparation.

DNA viromes were prepared to purify viral particles from their complex sample. Briefly, the clarified supernatant was filtered through a $0.45-\mu \mathrm{m}$ filter (Millipore, Molsheim, France), and free nucleic acids were digested with a cocktail of nucleases, i.e., 20U of Turbo DNAse (Life Technologies, Saint Aubin, France), 25U of RNAse A (Roche Diagnostics, Meylan, France), 25U of Benzonase ${ }^{\circledR}$ (Merck Millipore, Molsheim, France) and 20U of Exonuclease I (New England Biolabs, Évry, France), as previously described (Temmam et al., 2015). Finally, the digested supernatant was purified onto a discontinuous 66-30\% sucrose gradient and ultracentrifuged at $130,000 \mathrm{~g}$ for $2 \mathrm{~h}$ at $+4^{\circ} \mathrm{C}$ on a MLS-50 rotor (Beckman-Coulter, Villepinte, France). The viral fraction was harvested at the interphase between the 66 and $30 \%$ sucrose layers.

DNA was extracted from the purified viral fraction using Trizol LS ${ }^{\circledR}$ reagent (Life Technologies, Saint Aubin, France), according to the manufacturer's recommendations, and was randomly amplified using a Genomiphi V3 kit (GE Healthcare, Vélizy-Villacoublay, France) in two independent reactions. Amplification products were pooled and purified with Agencourt AMPure Beads (Beckman-Coulter, Villepinte, France) according to the manufacturer's protocol, eluted to a final volume of $15 \mu \mathrm{L}$ and sequenced using MiSeq Technology with the paired-end and barcode strategies according to a Nextera XT library kit in a $2 \times 300$ bp format (Illumina Inc., San Diego, USA).

\section{Bioinformatic Analyses of Viromes}

Raw reads were imported in pairs into CLC Genomics Workbench 6.0.1 program (CLC Bio, Aarhus, Denmark) and trimmed according to their quality score, the presence of ambiguities, and their length (reads $<50 \mathrm{nt}$ long were discarded). The pre-processed viral metagenomes are publicly available on the Metavir server (http://metavir-meb.univ-bpclermont.fr) under the project "Arthrovirome" project and on the MGRAST server (http://metagenomics.anl.gov/) with the identifiers 4604224.3, 4604225.3, and 4604226.3 for the STE0043, STE0044, and STE0045 DNA viromes, respectively.

Cleaned paired reads were assembled into contigs with the CLC Genomics program using the following parameters: a word size of $20 \mathrm{nt}$, minimum contig length of $200 \mathrm{nt}$, mismatch cost of 2, insertion/deletion cost of 3, length fraction of 0.5 , and similarity fraction of 0.8 . Contigs and non-assembled reads were then compared to the NCBI nucleotide database using the BlastN algorithm, with a minimum coverage of $50 \%$, minimum identity of $50 \%$, and an $E$-value $<10^{-5}$. Sequences with no significant hits according to the criteria described above were classified as "unknown." Contigs were then compared to the Megavirales database (Verneau et al. [METADIG: an automated pipeline to search for giant virus-related sequences in metagenomes. In revision]) using the Blast $\mathrm{X}$ program with a minimum coverage of $50 \%$, minimum identity of $50 \%$, and an $E$-value $<10^{-5}$. To confirm the specificity of the BlastX result, contigs were finally compared to the NCBI RefSeq viral database and to the whole NCBI database under the same criteria. The taxonomic 
assignment of contigs was conducted by selecting the best BlastX score result between the three Blasts run for each contig.

\section{Phylogenetic Analyses}

Contigs matching with amoeba-infecting giant viruses were extracted and translated using the FragGeneScan tool (Rho et al., 2010), according to the "short" and "complete" parameters. Predicted Open Reading Frames (ORF) were then compared to the Megavirales database using the BlastP program to identify Megavirales core genes. Phylogenetic analyses were performed on the amino-acid sequences of the RNA diphosphate reductase large sub-unit and the nucleotide sequence of the sub-unit common to RNA polymerase I-II-III, the DNA topoisomerase and the putative helicase C962R of Faustovirus.

Amino-acid and nucleotide sequences were retrieved from the GenBank database and aligned with the MUSCLE aligner (Edgar, 2004) implemented through MEGA6 (Tamura et al., 2013). The DNA/amino-acid substitutions model that best fitted the data were performed on MEGA6 (Tamura et al., 2013) and were considered for all phylogenetic analyses. We selected the best substitution model using the corrected Akaike information criterion. Phylogenetic trees were constructed by Maximum Likelihood (ML) implemented through the MEGA6 package software, according to the selected substitution model. Nodal support was evaluated by 1000 bootstrap replicates.

\section{Detection of Faustovirus in Animal, Human, and Environmental Samples}

Quantitative SYBR Green real-time PCR targeting the DNA polymerase of Faustovirus was performed with the Quantitect SYBR Green qPCR kit (Qiagen, Courtaboeuf, France), according to the manufacturer's recommendations, except that $400 \mathrm{nM}$ of forward ( $5^{\prime}$-CAAAGGCTATTGAGGCGATTTG-3') and reverse ( $5^{\prime}$-ATGATTGTGCTGCTAGGATACC-3') primers were used and mixed with $5 \mu \mathrm{l}$ of DNA. Annealing temperature was defined as $58^{\circ} \mathrm{C}$.

A standard curve was generated after extraction of serial dilutions of a flow cytometer-quantified Faustovirus. Briefly, the quantification was realized using a suspension of concentrationcalibrated Cytocount $^{\mathrm{TM}}$ fluorescent beads (Dako, Les Ulis, France) and the following formula: (number of counted particles / number of counted beads) $\times$ bead concentration (i.e., 1100 beads $/ \mu \mathrm{L}$ ), as previously reported (Khan et al., 2010). The resulting count was expressed in Virus-Like Particles (VLP) per $\mathrm{mL}$. Dilutions of the quantified virus were performed, and nucleic acids were extracted from each dilution and further used as template for the qPCR standard curve.

Primers targeting Faustovirus RNA polymerase and DNA topoisomerase were designed according to the metagenomes sequences: Fausto_RNApol_F (5'-TACGTCAAGCAGTAG CCAACG-3' $\left.{ }^{\prime}\right)$ Fausto_RNApol_R (5'-CTACTTGCCG CACAACAGCC- $3^{\prime}$ ), Fausto_DNAtopo_F (5'-CCAGC ACCATATGACACGCG-3') and Fausto_DNAtopo_R (5'-AATGTATGCGTTCGATTCGCC-3'). PCR targeting Faustovirus RNA polymerase, DNA topoisomerase and capsid (Reteno et al., 2015) were performed using the Hot
Star Taq DNA polymerase (Qiagen, Courtaboeuf, France). Annealing temperatures were $57^{\circ} \mathrm{C}, 57^{\circ} \mathrm{C}$, and $58^{\circ} \mathrm{C}$, respectively.

All PCR products were further analyzed on a $2 \%$ agarose gel, and bands of the expected size were extracted from the gel, purified using the QIAex Gel Extraction kit (Qiagen, Courtaboeuf, France) and sequenced with a Big Dye Terminator v1.1 Cycle Sequencing Kit (Life Technologies, Saint Aubin, France) and an ABI 3130 Genetic Analyzer (Life Technologies, Saint Aubin, France).

\section{Total Protein Extraction, Western Blot, and Global Proteomic Analyses}

Approximately $50 \mathrm{mg}$ of arthropods from the STE0043 sample were crushed in $300 \mu \mathrm{L}$ of lysis buffer (Tris- $\mathrm{HCl} 40 \mathrm{mM} \mathrm{pH} \mathrm{7.5,}$ SDS $2 \%(\mathrm{w} / \mathrm{v})$, DTT $60 \mathrm{mM}$ ) with two 3-mm tungsten beads and a TissueLyser at $25 \mathrm{~Hz}$ for $2 \mathrm{~min}$ (Qiagen, Courtaboeuf, France) before heating at $95^{\circ} \mathrm{C}$ for $5 \mathrm{~min}$. Proteins from the clarified supernatant were precipitated using the PlusOne 2-D Clean-Up Kit (GE Healthcare, Vélizy-Villacoublay, France). The final pellet was resuspended in $200 \mu \mathrm{L}$ of solubilization buffer (Urea $8 \mathrm{M}$, Thiourea 2M, $100 \mathrm{mM} \mathrm{NaCl}, 25 \mathrm{mM}$ Tris, $\mathrm{pH}$ 8.2) and dialyzed twice using Slide-ALyzer Dialysis Cassettes 2K MWCO (Pierce Biotechnology, Rockford, USA) against $1 \mathrm{~L}$ of $50 \mathrm{mM}$ ammonium bicarbonate $\mathrm{pH} 7.4$, Urea $1 \mathrm{M}$ ( $7 \mathrm{~h}$ and overnight). Dialyzed fractions were collected and proteins were quantified by Bradford assay using Coomassie (Biorad, Marnes-la-Coquette, France). The dialyzed fraction was subsequently used as a template for global proteomics and western blot analyses.

Two hundred micrograms of soluble proteins were fractionated on a $12 \%$ polyacrylamide gel electrophoresis then revealed by silver staining. Additionally, resolved proteins were transferred onto a nitrocellulose membrane (Trans-blot Transfer Medium, Biorad, Hercules, CA, USA) at $100 \mathrm{~V}$ for $1 \mathrm{~h}$ using a semi-dry transfer unit (Hoefer TE 77, GE Healthcare, Vélizy-Villacoublay, France). Membranes were then blocked in PBS supplemented with $0.3 \%$ Tween-20 and 5\% non-fat dried milk (PBS-Tween-Milk) for $90 \mathrm{~min}$, and incubated with mouse polyclonal anti-Faustovirus antibodies (1:1000). The immunoreactive bands were detected using a peroxidaseconjugated goat anti-mouse immunoglobulin (GE Healthcare, Vélizy-Villacoublay, France) diluted to 1:5000 in the blocking buffer for $1 \mathrm{~h}$ at room temperature. Three fifteen minutes washes were applied between each step. Immunostained bands were visualized with the chemiluminescence-based kit, as described by the manufacturer (GE Healthcare, Vélizy-Villacoublay, France). The resulting signal was captured by a Fusion FX7 imaging system (Vilber Lourmat, France).

Six pieces corresponding to immunoreactive bands were excised from silver stained gel and subject to mass spectrometry (MS) analysis. Briefly, after several washes, the proteins extracted from the gel were reduced, alkylated and digested with trypsin, as described above. Tryptic peptides were extracted with acetonitrile $100 \%$; the extraction solution was collected and incubated at $45^{\circ} \mathrm{C}$ to evaporate the acetonitrile and to concentrate it prior to MS analysis. An additional global proteomic analysis was conducted. Briefly, $200 \mu \mathrm{g}$ of total soluble proteins were 
reduced and alkylated with iodoacetamide. Protein digestion was performed by adding $8 \mu \mathrm{g}$ of sequencing-grade trypsin solution (Promega, Charbonnières, France) to alkylated proteins and incubated overnight at $37^{\circ} \mathrm{C}$. The digested sample was then desalted using Pierce Detergent Removal Spin Columns (Thermo Fisher Scientific, Illkirch, France) and analyzed by mass spectrometry, as described hereafter.

A NanoAcquity UPLC System (Waters, Saint-Quentin En Yvelines, France) was coupled with a Synapt-G2 Si HDMS with Traveling-Wave-Ion-Mobility Mass Spectrometry instrument (TWIM-MS; Waters, Saint-Quentin En Yvelines, France). Chromatographic separation was performed on an NanoAcquity UPLC BEH130 C18 column $(1.7 \mu \mathrm{m}, 100 \mu \mathrm{m} \times 100 \mathrm{~mm}$; Waters, Saint-Quentin En Yvelines, France) preceded by a Symmetry C18 trapping column $(5 \mu \mathrm{m}, 180 \mu \mathrm{m} \times 20 \mathrm{~mm})$; both were placed in a $40^{\circ} \mathrm{C}$ oven. The injection volume was set to $2 \mu \mathrm{L}$ for the digested soluble proteins $(200 \mathrm{ng} / \mu \mathrm{L})$ and $4 \mu \mathrm{L}$ for gel-extracted proteins. The mobile phase consisted of water (A) and acetonitrile (B) both in $0.1 \%$ formic acid. Samples were trapped over $3 \mathrm{~min}$ with 99.9\% $\mathrm{A}$ and $0.1 \% \mathrm{~B}$. The separation gradient was as follows: 0-100 min, linear from $95 \% \mathrm{~A}, 5 \% \mathrm{~B}$, to $60 \% \mathrm{~A}$, and $40 \% \mathrm{~B}$; 100-107 min. Mass spectrometry experiments were performed in positive ion mode and in resolution mode. The settings of the instruments were automatically optimized to obtain the best resolution. The ion source parameters were capillary voltage $3 \mathrm{kV}$, sampling cone voltage $40 \mathrm{~V}$, ion source temperature $90^{\circ} \mathrm{C}$ and cone gas flow $50 \mathrm{~L} / \mathrm{h}$. Transfer collision low energy was set to $5 \mathrm{~V}$ while trap collision low energy was set to $4 \mathrm{~V}$. The high energy ramp was applied from 4 to $5 \mathrm{~V}$ for the trap collision and from 19 to $45 \mathrm{~V}$ for the transfer collision, enabling fragmentation of the ions after the ion mobility cell and before the time-offlight (TOF) MS. The instrument was previously calibrated in the mass range of 50-2000 Da using GFP fragments $(0.2 \mathrm{pmol} / \mu \mathrm{L})$. Data were processed using ProteinLynx Global Server version 3.0.1 (Waters, Saint-Quentin En Yvelines, France). Processing parameters were 250 counts for the low energy threshold, 100 counts for the elevated energy threshold and 750 counts for the intensity threshold.

Databases used to compare spectra combined data from Mammalia (2015/Feb/09, Swissprot, 66,370 sequences), Dipteria (2015/Feb/09, Swissprot, 6607 sequences), and giant viruses (2015/Feb/06, TrEMBL and not published giant viruses sequences, 14,866 sequences). An additional database was generated using predicted ORFs generated following the FragGeneScan analysis of giant viral contigs of the three metagenomes. A cut-off was used to remove the matches with only one and two peptides and the option of Merge Data was used with the six gel pieces.

\section{Transmission Electron Microscopy (TEM)}

Approximately $50 \mathrm{mg}$ of arthropods from the STE0043 sample were washed in $70 \%$ ethanol, as previously described (Slimani et al., 2013) and crushed in $2 \mathrm{~mL}$ of sterile EMEM medium (Life Technologies, Saint Aubin, France) using two 3-mm tungsten beads and a TissueLyser at $25 \mathrm{~Hz}$ for $2 \mathrm{~min}$ (Qiagen, Courtaboeuf, France). The supernatant was harvested after a low speed clarification and subsequently filtered through a $0.8-\mu \mathrm{m}$ filter
(Millipore, Molsheim, France). The resulting supernatant was purified onto a discontinuous $66-30 \%$ sucrose gradient and ultracentrifuged at $130,000 \mathrm{~g}$ for $2 \mathrm{~h}$ at $+4^{\circ} \mathrm{C}$, as described above.

The viral fraction was harvested at the interphase between the 66 and $30 \%$ sucrose layers and fixed for $1 \mathrm{~h}$ at $+4^{\circ} \mathrm{C}$ with $2 \%$ final glutaraldehyde. The fixed viral fraction was then diluted to a final volume of $4 \mathrm{~mL}$ in PBS, and adsorbed directly onto formvar carbon films on 400 mesh nickel grids (FCF400-Ni, EMS) by ultracentrifugation at $130,000 \mathrm{~g}$ for $1 \mathrm{~h}$ at $+4^{\circ} \mathrm{C}$, as previously described (Sime-Ngando et al., 1996). Grids were stained for $10 \mathrm{~s}$ with $1 \%$ molybdate solution in filtered water at room temperature. Electron micrographs were obtained on a Tecnai G2 transmission electron microscope (FEI) operated at $200 \mathrm{keV}$ equipped with a $4096 \times 4096$ pixel resolution Eagle camera (FEI).

\section{Isolation of Viruses on Amoebae}

Approximately $50 \mathrm{mg}$ of arthropods from the STE0043 sample were washed in $70 \%$ ethanol, as previously described (Slimani et al., 2013), then with sterile Page's amoebal saline (PAS) solution, and finally crushed in $3 \mathrm{~mL}$ of PAS buffer.

$V$. vermiformis (CDC19 strain) amoebae were used to isolate giant viruses from arthropods, as reported by Pagnier et al. (2013), except that Vancomycin $10 \mu \mathrm{g} / \mathrm{mL}$, Ciprofloxacine $20 \mu \mathrm{g} / \mathrm{mL}$, Imipenem/cilastatine $10 \mu \mathrm{g} / \mathrm{mL}$, Doxycycline $20 \mu \mathrm{g} / \mathrm{Ml}$, and Voriconazole $20 \mu \mathrm{g} / \mathrm{mL}$ were added to the amoebal suspensions to prevent bacterial and fungal contamination. Briefly, amoebae were cultivated in peptoneyeast extract-glucose (PYG) medium and sub-cultured every 2 days. $5 \times 10^{5}$ amoebae $/ \mathrm{mL}$ were concomitantly plated in a 12 -well microplate with $100 \mu \mathrm{L}$ of the sample suspension and incubated at $30^{\circ} \mathrm{C}$ for 3 days. At Day 3 post-infection, the primo-culture was sub-cultured onto a fresh amoebal microplate suspension under the same conditions. The primary cultures and sub-cultures were screened daily for a cytopathogenic effect (CPE) using an inverted microscope and if CPEs were observed, fresh amoeba cells were cytospinned with $100 \mu \mathrm{L}$ of viral supernatant and further stained with Gimenez and Gram stains, followed by additional Hemacolor staining (Merck, Darmstadt, Germany).

Additionally, $100 \mu \mathrm{L}$ of positive CPE supernatant was used to extract DNA using the phenol chloroform isoamyl alcohol extraction procedure (Life Technologies, Saint Aubin, France) according to the manufacturer's protocol, and PCRs targeting Faustovirus were conducted, as described above.

\section{RESULTS}

\section{Presence and Diversity of Sequences Related to Giant Viruses in the Virome of Biting Midges}

The DNA virome of the STE0043, STE0044, and STE0045 samples were sequenced using Illumina MiSeq technology. After trimming, the total number of reads was $1,517,965$, $2,163,868$, and 2,265,552 reads, respectively (Table 1), with 46.29, 76.01 , and $48.50 \%$ of sequences having homologies after BlastN 
TABLE 1 | Sequencing data of the virome datasets.

\begin{tabular}{|c|c|c|c|}
\hline & $\begin{array}{c}\text { STE0043 } \\
\text { Culicoides sp. }\end{array}$ & $\begin{array}{c}\text { STE0044C. imicola } \\
\text { qengorged }\end{array}$ & $\begin{array}{l}\text { STE0045 } \\
\text { C. imicola } \sigma^{x} \nmid \text { non- } \\
\text { engorged }\end{array}$ \\
\hline Raw reads & $1,520,202$ & $2,173,228$ & $2,267,752$ \\
\hline Cleaned reads & $1,517,965$ & $2,163,868$ & $2,265,552$ \\
\hline Contigs & 19,771 & 29,995 & 28,309 \\
\hline Singletons & 85,185 & 134,230 & 122,805 \\
\hline $\begin{array}{l}\text { Average contig } \\
\text { length }\end{array}$ & 615 bp & $587 \mathrm{bp}$ & $581 \mathrm{bp}$ \\
\hline $\begin{array}{l}\text { Total assigned } \\
\text { reads: }\end{array}$ & 702,730 & $1,644,792$ & 1,098,862 \\
\hline eukaryote & 576,221 & $1,457,350$ & 781,498 \\
\hline $\begin{array}{l}\text { prokaryote } \\
\text { (bacteria }+ \\
\text { archaea) }\end{array}$ & 122,075 & 164,982 & 303,928 \\
\hline virus & 4434 & 22,460 & 13,436 \\
\hline Total giant viruses: & 3465 & 20,745 & 4684 \\
\hline Faustovirus & 3146 & 8383 & 3490 \\
\hline Mimiviridae & 317 & 12,362 & 1164 \\
\hline $\begin{array}{l}\text { Non-classified } \\
\text { giant viruses }\end{array}$ & 2 & 0 & 30 \\
\hline Other viruses: & 969 & 1715 & 8752 \\
\hline Nudiviridae & 307 & 0 & 6237 \\
\hline Poxviridae & 182 & 42 & 34 \\
\hline Siphoviridae & 182 & 503 & 808 \\
\hline $\begin{array}{l}\text { Non-classified } \\
\text { phages }\end{array}$ & 156 & 277 & 240 \\
\hline Myoviridae & 60 & 554 & 785 \\
\hline Papillomaviridae & 41 & 100 & 2 \\
\hline Iridoviridae & 29 & 0 & 0 \\
\hline Podoviridae & 4 & 45 & 29 \\
\hline Phycodnaviridae & 2 & 90 & 133 \\
\hline Polydnaviridae & 2 & 0 & 0 \\
\hline Retroviridae & 2 & 92 & 16 \\
\hline $\begin{array}{l}\text { Non-classified } \\
\text { plant viruses }\end{array}$ & 2 & 0 & 0 \\
\hline Ascoviridae & 0 & 12 & 2 \\
\hline Herpesviridae & 0 & 0 & 315 \\
\hline Inoviridae & 0 & 0 & 149 \\
\hline Iflaviridae & 0 & 0 & 2 \\
\hline
\end{tabular}

against GenBank nt database, respectively. Eukaryotic sequences represented more than $70 \%$ of the total assigned reads in the STE0043, STE0044, and STE0045 metagenomes, mainly identified as human and arthropod reads (Table 1).

Among the total assigned reads, 4434 (STE0043), 22,460 (STE0044), and 13,434 (STE0045) sequences were related to viruses (Table 1). Most viral sequences were identified as doublestranded DNA viruses, and single-stranded DNA viral sequences were only detected in STE0045 non-engorged male and female C. imicola virome. Sequences related to amoeba-infecting giant viruses from the Mimiviridae family, Faustovirus and the nontaxonomically classified Pandoravirus represented the majority of viral reads, with more than 78,92 , and $34 \%$ of total viral reads, respectively, for STE0043, STE0044, and STE0045 viromes. The most represented virus was Faustovirus, with more than 90, 40, and $74 \%$ of total giant viral reads, respectively (Table $\mathbf{1}$ ).

The presence of Faustovirus in each sample was confirmed by PCR specifically targeting the DNA polymerase, the viral capsid, the RNA polymerase and the DNA topoisomerase genes of the virus. PCR amplification products were obtained for the three metagenomes (see Supplemental Figure 1 for the capsid amplification) and Faustovirus amplifications were confirmed by sequencing.

The presence of amoeba-infecting giant viral sequences was searched on previously published arthropods metagenomes available in public databases (Table 2). Sequences from both hematophagous (mosquitoes, hard ticks, and body lice) and non-hematophagous (termites and whiteflies) arthropods were assembled into contigs and compared to an in-house giant viral database. Mosquito microbiomes showed the presence of Mimiviridae and Pandoraviridae-related contigs in all of the five studies, although these came from arthropods sampled at different time points in different locations. Hard ticks and experimentally-infected body lice metagenomics revealed also the presence of Mimiviridae-related contigs. In contrast, termites and whiteflies metagenomic datasets did not present any amoeba-infecting giant viral contigs. No Faustovirusrelated sequences were retrieved in metagenomes, either from hematophagous or non-hematophagous arthropods.

\section{Phylogenetic Analyses of the Faustovirus-Like Virus Identified in the Virome of Biting Midges}

Contigs matching with Faustovirus sequences were extracted and translated. Results of the predicted ORFs are presented in Table 3. Phylogenetic reconstructions were performed on several conserved genes: the RNA diphosphate reductase large subunit and the sub-unit common to RNA polymerase I-II-III that were found in the three biting midges' metagenomes, the DNA topoisomerase only detected on the STE0043 Culicoides sp. virome and the putative helicase C962R, both present in the STE0044 C. imicola engorged female and the STE0045 C. imicola non-engorged male/female viromes.

Phylogenetic analyses performed on the sub-unit common to RNA polymerase I-II-III (Figure 2A) and on the RNA diphosphate reductase large sub-unit genes (Figure 2B) showed that the biting midges' Faustovirus grouped with other Faustoviruses isolated from French, Senegalese and Lebanese sewage. More precisely, Senegalese biting midges' Faustovirus formed a cluster with Dakar sewage Faustovirus, supported by high bootstrap nodes (100 and 95, respectively). These results were confirmed with phylogenetic analyses performed on the DNA topoisomerase (Supplemental Figure 2A) and the putative helicase C962R (Supplemental Figure 2B) genes.

Phylogeny performed on the RNA diphosphate reductase large sub-unit gene allowed distinguishing a specific cluster composed of biting midges Faustovirus only within the Senegalese Faustovirus clade, with a high bootstrap value of 78 (Figure 2B). 
TABLE 2 | Search for the presence of amoeba-infecting giant viral sequences in the metagenomes of other arthropods.

\begin{tabular}{|c|c|c|c|c|c|c|}
\hline Arthropods & $\mathrm{Nb}$ of total reads & $\mathrm{Nb}$ of contigs & Sequencing method & Type of metagenome & $\begin{array}{l}\text { Amoeba-infecting giant viral } \\
\text { contig (nb) }\end{array}$ & References \\
\hline \multirow[t]{4}{*}{ Mosquitoes } & $1,575,043$ & 1964 & Roche 454 FLX & RNA shotgun & Mimiviridae (1) & Bishop-Lilly et al., 2010 \\
\hline & $26,403,284$ & 89,744 & |llumina GA II & RNA shotgun & Mimiviridae (8) Pandoraviridae (10) & Chandler et al., 2014 \\
\hline & $217,330,434$ & 311,750 & Illumina HiSeq 2000 & RNA shotgun & Mimiviridae (13) Pandoraviridae (19) & Chandler et al., 2015 \\
\hline & $1,576,489$ & 15,666 & Roche 454 GS20 & DNA shotgun & Mimiviridae (1) Pandoraviridae (2) & Ng et al., 2011 \\
\hline Whiteflies & $1,427,809$ & 193 & |llumina GA II & RNA shotgun & 0 & Rosario et al., 2014 \\
\hline Termites & - & 57,641 & Sanger & DNA shotgun & 0 & Warnecke et al., 2007 \\
\hline Hard ticks & 350,329 & 31,881 & Roche 454 FLX & DNA shotgun & Mimiviridae (1) & Nakao et al., 2013 \\
\hline
\end{tabular}

TABLE 3 | Predicted ORFs for Faustovirus detected in the three metagenomes.

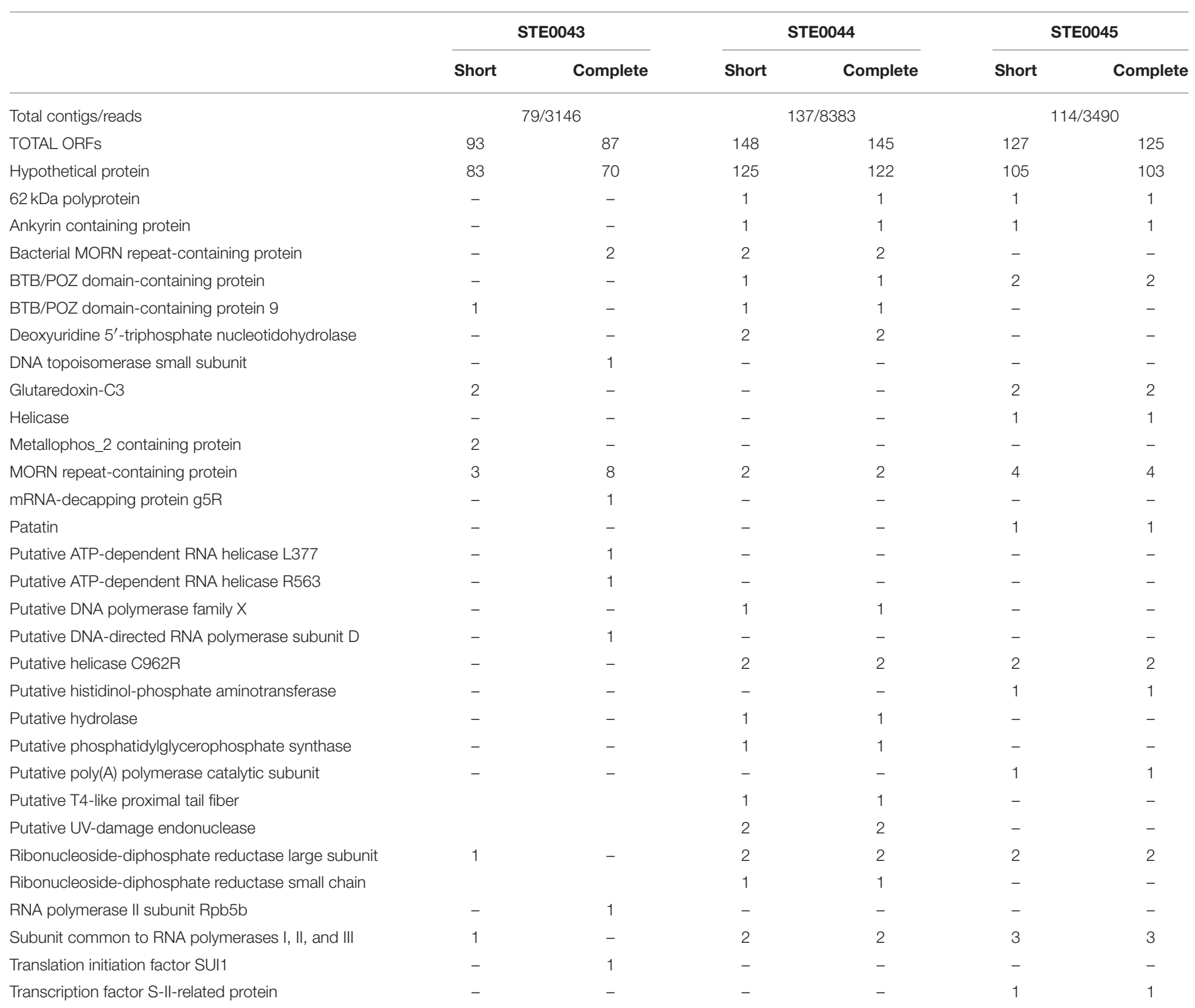



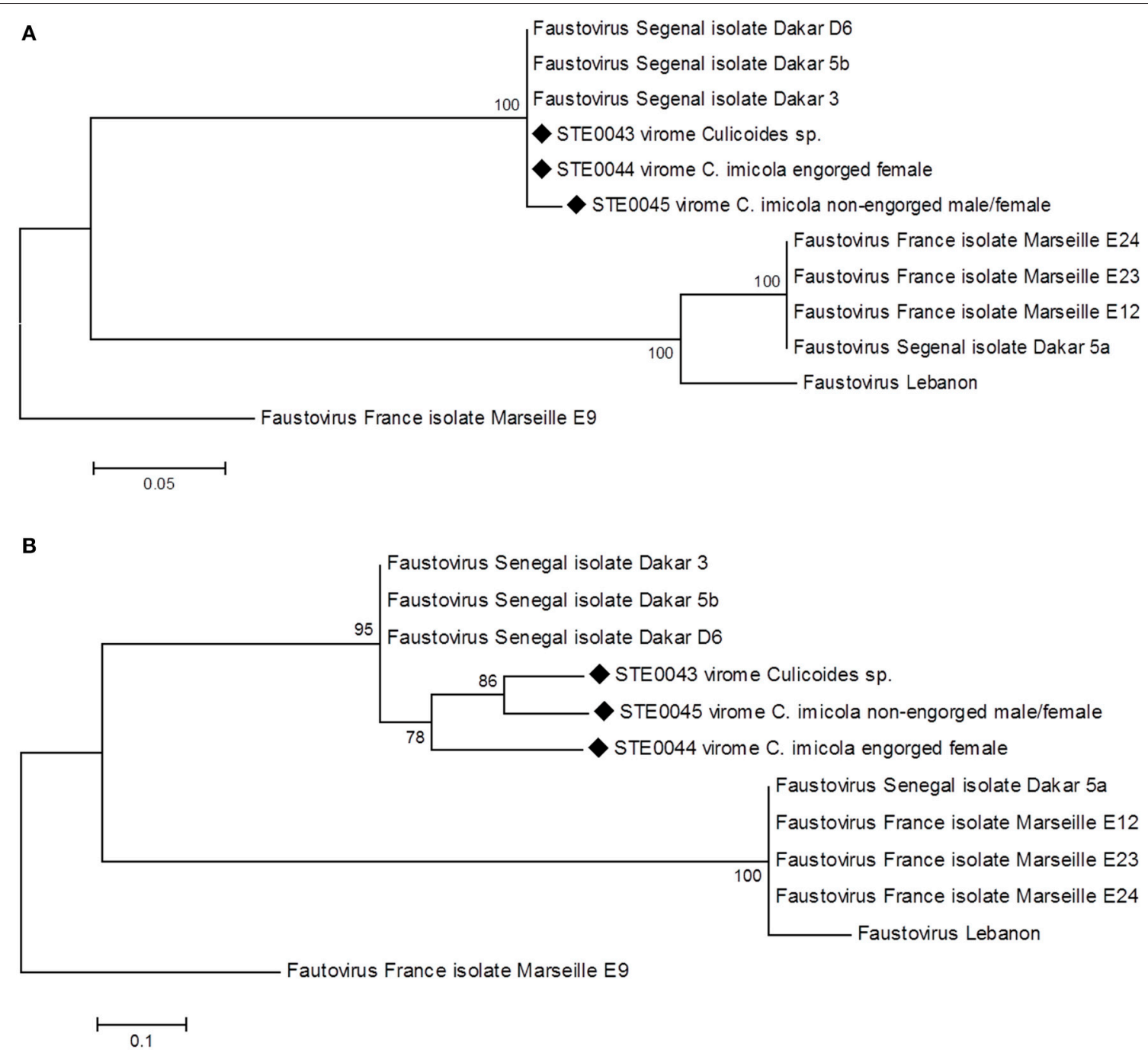

FIGURE 2 | Phylogenetic reconstruction of Faustovirus detected in biting midges' viromes based on the (A) nucleotide sequence of the sub-unit common to RNA polymerase I-II-III (substitution model: Kimura-2-parameters) (B) amino-acid sequence of the RNA diphosphate reductase large sub-unit (substitution model: JTT+G, $G=3$ ).

\section{Observation of Virus-Like Particles by Transmission Electron-Microscopy and Isolation of a Faustovirus-Like Virus from Biting Midges}

Viral particles purified from biting midges were negatively stained and observed by transmission electron microscopy (Figure 3). Virus-like particles were observed with different morphologies and diameters, ranging from 600 (Figure 3A) to $200 \mathrm{~nm}$ (Figure 3D). Some of the observed virions had a diameter (approximately $200 \mathrm{~nm}$ ) and morphology (icosahedral capsid) compatible with that of Faustovirus (Figure 3D).

$V$. vermiformis protists was used in an attempt to isolate Faustovirus-related viruses detected in STE0043 Culicoides sp. virome. One $V$. vermiformis sub-culture was Faustovirus PCRpositive at Day 3 post-infection, and sequencing of a fraction of the capsid gene confirmed that the isolated virus was Faustovirus.
However, successful viral production was impaired due to the high bacterial load present in the culture, originating from the arthropods' guts.

\section{Global Proteomics of Biting Midges}

Western blot analysis of STE0043 proteins revealed an immunoreactive smear, between 260 and $50 \mathrm{kDa}$, with antiFaustovirus polyclonal antibodies (Figure 4B). The smear was due to a high load of proteins $(200 \mu \mathrm{g})$ allowing the detection of viral proteins in very low abundance in these arthropods. As shown in Figure 4C, with a loading of $5 \mu \mathrm{g}$, no detection was possible in arthropods, although the positive control revealed reactive bands. Within this smear, a putative band at $60 \mathrm{kDa}$ was observed for Faustovirus, possibly corresponding to the viral capsid (arrow of Figure 4B). Six pieces of electrophoresisfractioned proteins among the immunoreactive smear were 


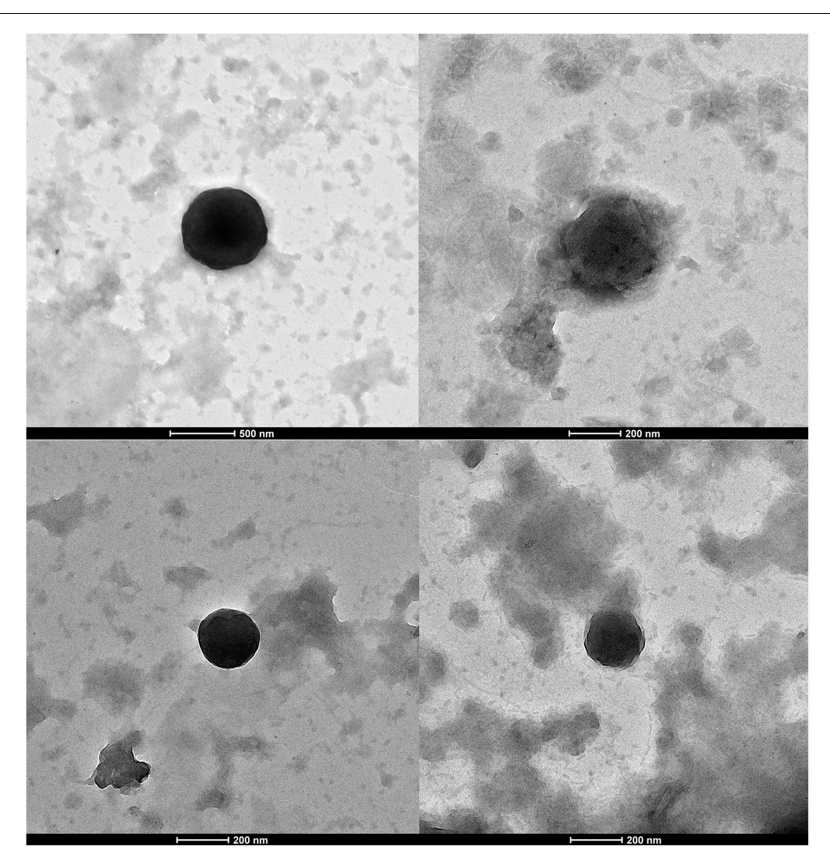

FIGURE 3 | Negative staining electron microscopy imaging of viral particles from Culicoides sp. biting midges' samples. Scale bars are indicated under the images.

subsequently extracted from the gel and analyzed by proteomics (Figure 4A).

The global proteomic analysis of the six immunoreactive bands identified 4576 different peptides. Many peptides were not identified, due to incomplete databases. The major identified proteins were related to blood tissues: indeed, nearly a quarter of the total identified peptides represented blood proteins components, i.e., serum albumin, hemoglobin and fibrinogen, which represented $5.44,15.57$, and $0.90 \%$ of the total identified peptides, respectively. Numerous arthropod-borne peptides (33.77\%) were also identified, and more than two thirds of identified peptides were related to the arthropods' major blood meal hosts: Bovidae represented $25.00 \%$ of the total identified peptides, $15.77 \%$ for humans, and $11.42 \%$ for Rodentia. Less abundantly, $2.95 \%$ of peptides were identified as coming from horses, $2.80 \%$ from pets (cats and dogs), 1.99\% from Lagomorpha (mainly rabbits), $1.17 \%$ from swine, $1.05 \%$ from primates, and $0.87 \%$ from Chiropera. Interestingly and although no peptide matching with Faustovirus was detected, three peptides matched with the viral proteome of Saudian virus, a new giant virus isolated from sewage, were detected.

Similar results were obtained for the whole proteomic analysis, with slight differences in the proportions of identified peptides, except that four and seven peptides were obtained for Kroon virus and Courdo11 Mimiviridae proteins, respectively (Yoosuf et al., 2014; Boratto et al., 2015). In addition, Mimiviridae-related sequences were obtained in the metagenomes (data not shown). No match with Faustovirus was obtained.

No hit were obtained when comparing the peptides to the virome-predicted ORFs database.

\section{Detection of Faustovirus in Animals and Environmental Water}

The serum from 14 cattle and their associated hard ticks, 13 rodents (four suckling mice and nine Arvicanthis sp.), well water from Dielmo and Ndiop, and Néma river water recovered in Dielmo were collected and used to screen for the presence of Faustovirus.

The presence of Faustovirus was detected in five over 13 rodents tested: two were from suckling mice trapped in Ndiop and three were from Arvicanthis sp. rodents trapped in Ndiop $(N=2)$ and Dielmo $(N=1)$ respectively. Additionally, Faustovirus was detected in two over 14 cattle sera (one from Ndiop on a healthy cattle and one from Dielmo on a lumpy skin disease-infected veal). Faustovirus was also present in environmental water in both well and river waters from Dielmo and well water from Ndiop.

Two pools of hard ticks (Boophilus sp. and Rhipicephalus evertsi) collected from the same cattle in Keur Samba Gueye, a village close to Ndiop, were also positive for Faustovirus although the animal serum was negative. One pool of Amblyomma sp. hard ticks, collected from cattle in Ndiop, and one pool of Ornithodoros sonrai soft ticks, collected from rodents' nests in Keru Serigne Korka (a village located $12 \mathrm{~km}$ north-east of Dielmo) were also positive.

These positive detections were all confirmed by sequencing the portion of the DNA polymerase and the capsid genes of Faustovirus. Phylogenetic analyses of rodent-borne, cattle-borne, and water-borne Faustovirus performed on the capsid gene confirmed the relatedness of environmental and mammalian Faustovirus with arthropod-borne Faustovirus, but was not sufficiently discriminant to specifically define clusters of Senegalese Faustovirus (data not shown).

Viral loads of Faustovirus in PCR-positive animals were estimated according to the tissue sample (Figure 5A) and the animal species (Figure 5B). All harvested organs were positive for Faustovirus, in viral loads ranging from $3.49 \times 10^{5} \mathrm{VLP} / \mathrm{mL}$ (lung) to $8.01 \times 10^{6} \mathrm{VLP} / \mathrm{mL}$ (kidney), except for intestine samples which were all negative, even when the extracted DNA was diluted in case of the presence of inhibitors. Interestingly, Faustovirus quantification in kidneys was similar in scale to that in the bladder or urine samples $\left(4.21 \times 10^{6} \mathrm{VLP} / \mathrm{mL}\right)$. Faustovirus load in cattle sera was estimated at $5.96 \times 10^{6}$ $\mathrm{VLP} / \mathrm{mL}$. Biting midges non-amplified viromes were detected with the highest viral loads, estimated at $2.47 \times 10^{7} \mathrm{VLP} / \mathrm{mL}$ (Figure 5A). No major difference was observed when analyzing the relative abundance of Faustovirus according to animal species (Figure 5B). Arvicanthis-positive animals presented the lowest $\left(1.67 \times 10^{6} \mathrm{VLP} / \mathrm{mL}\right)$ and biting midges the highest $\left(2.47 \times 10^{7}\right.$ $\mathrm{VLP} / \mathrm{mL}$ ) Faustovirus load.

\section{Detection of Faustovirus in Humans}

The serum of 112 febrile patients with no known etiology and 51 healthy people was screened for the presence of Faustovirus with the DNA polymerase targeted system. A total of 11 out of $112(9.82 \%)$ febrile patients and six out of 51 (11.76\%) healthy persons were positive. Sequencing of the small PCR product (99 bp) confirmed the positive detection of Faustovirus on $57 \mathrm{bp}$. 


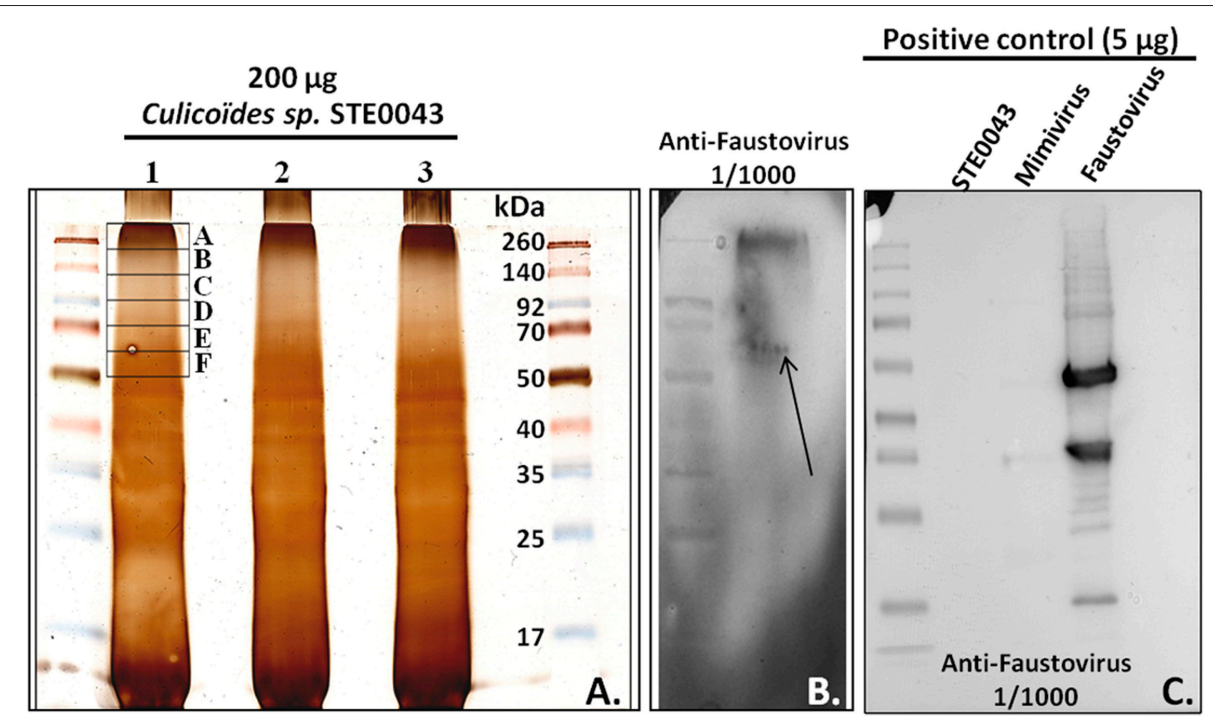

FIGURE 4 | Western blot analysis. (A) Silver staining. (B) Staining with anti-Faustovirus polyclonal antibodies on arthropods sample. (C) Positive control of Faustovirus western blot with a loading of $5 \mu \mathrm{g}$ of proteins.
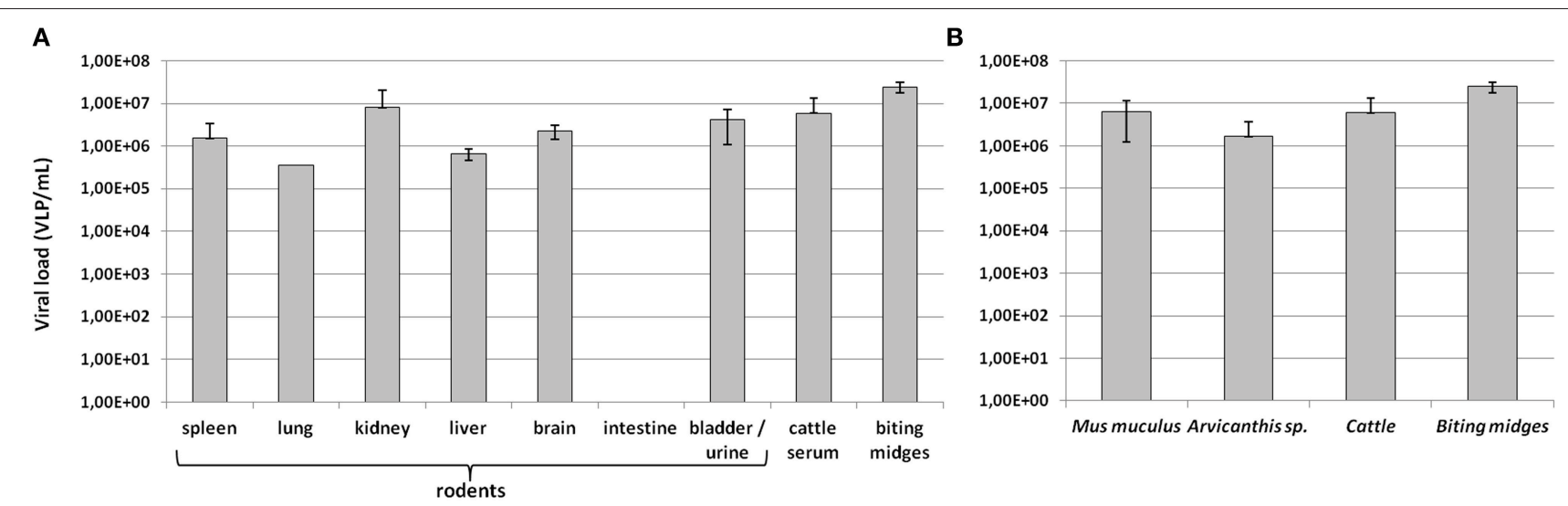

FIGURE 5 | Quantification of Faustovirus viral loads according to (A) tissue samples (B) animal species. Viral loads are expressed in log 10 VLP/mL.

Capsid and DNA topoisomerase amplifications of Faustoviruspositive human sera were negative and RNA polymerase amplification of Faustovirus-positive human sera resulted in a non-specific multi-band amplification (data not shown).

\section{DISCUSSION}

Amoeba-infecting giant viruses have been isolated in a wide variety of biomes, mostly in environmental (i.e., soil and water) samples (Pagnier et al., 2013). Various amoeba-infecting giant viruses have also been detected in animals, such as in arthropod larvae (Boughalmi et al., 2013a), in the leech Hirudo medicinalis (Boughalmi et al., 2013b) or in the sera of cattle and monkeys (Dornas et al., 2014). Recently, the first amoeba-infecting giant virus belonging to the Asfarviridae family, Faustovirus, was reported in sewage in various geographical locations (Reteno et al., 2015). The unique other member of the Asfarviridae family is the ASFV, a tick-borne virus. In this study we detected and isolated for the first time Faustovirus in adults biting midges and their blood meal-associated mammals.

As part of a global study of viral communities existing in biting midges, pools of Culicoides sp., engorged female C. imicola and non-engorged male and female C. imicola were collected and their corresponding DNA viromes were sequenced. Results revealed the presence of sequences related to giant viruses, mainly Faustovirus with more than 90, 40, and $74 \%$ of total giant viral reads, respectively. The presence of an amoebainfecting Asfarviridae-like virus in adult biting midges leads us to question on the mode of contamination of adult biting midges. Ceratopogonidae are arthropods with an aquatic and semiaquatic larval stage, leading to possible contact with amoebae and their associated giant viruses during the larval stage, and a putative trans-stadial transmission of free viral particles or infected amoebae. Moreover, Evans and Schwarz (2011) reported 
the infection of adult honeybees by Malpighamoeba mellificae, a protozoan developing in the Malpighi tubes of honeybees. We can therefore hypothesize that, adult biting midges could either be infected at the larval or during the adult stage, either with free viral particles or infected amoebae. The mode of contamination of adult biting midges is currently unknown but further studies regarding the presence of Faustovirus in all stages of development of arthropods may help to solve this question.

The engorged female C. imicola virome showed the highest abundance of sequences related to Faustovirus, with significant differences with the non-engorged metagenome, suggesting a possible additional viral load of the arthropod via the blood meal of female biting midges. We then searched for the presence of sequences related to Faustovirus and other giant viruses in publicly available arthropods metagenomic datasets. Our results showed that, although in low abundance, giant viral contigs were detected in other arthropods, except for Faustovirus, never detected elsewhere than in the biting midges virome. Mosquitoes and body lice presented similar abundances of Mimiviridae- and Pandoraviridae-related contigs and hard ticks presented similar abundance of Mimiviridaerelated contigs, whereas termites and whiteflies present no giant viral sequence. One should note that mosquitoes, body lice and hard ticks are hematophagous arthropods whereas termites and whiteflies are non-hematophagous arthropods, suggesting again the putative role of blood meal in the presence of giant viruses in adult arthropods. Further proteomic analysis of the pool of Culicoides sp. revealed the presence of Bovidae, Rodentia, and human blood-related proteins. As a consequence we subsequently screened for the presence of Faustovirus in human sera, cattle sera and rodent organs, and detected five Faustovirus-positive rodents and two Faustovirus-positive cattle, confirming the possible contamination of female biting midges via their blood meal. Additionally, we detected three Faustoviruspositive cattle-associated engorged hard ticks, again confirming possible infection of arthropods via their blood meal.

Interestingly, we reported high levels of Faustovirus either in rodent tissue or cattle sera (Figure 5), and the highest viral loads were found in rodents' kidney and urine samples, suggesting a possible excretion of Faustovirus by rodents in the environment. Finally, the Néma River and the well water from Dielmo and Ndiop were all positive for Faustovirus, suggesting a possible source of contamination of humans and animals via recreational or drinking water. In sub-Saharan countries, such as Senegal, biting midges usually feed on livestock but also on humans, resulting in the vector-borne transmission of pathogens to animals and humans. In this study we reported the detection of Faustovirus in human sera harvested from febrile patients and from healthy people, with no significant difference in the prevalence between the two groups. Although we could not conclude on a putative pathogenic role of Faustovirus, the questions of the mode of infection to humans have to be addressed: is Faustovirus vector-transmitted? And if so, what kind of arthropod can transmit the virus? Or do humans acquire Faustovirus via an environmental source (water, urines of rodents, etc)? The possible reservoir role of rodents in the viral cycle of Faustovirus, both in humans and arthropods, requires further investigations, as for the vector competence of arthropods for Faustovirus.

Faustovirus-related sequences were the most abundant in all viromes. Although no capsid sequence was detected in the metagenomes, we successfully amplified a fragment of the capsid gene and confirmed by sequencing (Supplemental Figure 1). Western blot analysis of Culicoides sp. proteins using Faustovirus antibodies highlighted a band at the expected size of the capsid protein (Figure 4B), and further mass spectrometry sequencing identified giant viral peptides, although not related to Faustovirus. Additionally, the observation of viral particles by transmission electron microscopy with a size and shape compatible with Faustovirus, and further successful isolation of Faustovirus conducted on $V$. vermiformis, a protist commonly found in human environments (Nazar et al., 2012; Coşkun et al., 2013; Niyyati et al., 2014), confirmed the presence of infectious viral particles in the Culicoides sp. pool of biting midges. Phylogenetic analyses performed on several core genes revealed that Faustovirus-like viruses detected in the three biting midge viromes branch together in a cluster formed by Dakar 5b, Dakar 3, and Dakar D6 Faustovirus (Figure 2), viruses that were previously isolated in sewage from Dakar, Senegal (Reteno et al., 2015). According to the phylogenetic analysis conducted on the capsid gene, rodent-borne, cattleborne and water-borne Faustovirus clustered together with arthropod-borne Faustovirus. Unfortunately, this portion of the genome of Faustovirus was not sufficiently discriminant to be able to refine the classification of mammalian, arthropod and environmental Faustovirus. Complete full genome sequencing and characterization of these viruses will enable the phylogenetic relationships between arthropod-associated Faustovirus, environmental/mammalian Faustoviruses and human Faustovirus to be refined.

Faustovirus is a recently described giant virus infecting V. vermiformis amoebae (Reteno et al., 2015), whose close relative is the ASFV, the only member of the Asfarviridae family. Asfarviridae are tick-borne dsDNA viruses transmitted by Ornithodoros sp. soft ticks and responsible for the African swine fever, a highly contagious and fatal pig infection (Burrage, 2013; Hubálek et al., 2014). Recently, hard ticks have been suspected to be capable of transmitting the virus but without success, although viral DNA was detected up to 8 weeks post-inoculation (de Carvalho Ferreira et al., 2014). In our study we report the detection and isolation of an Asfarviridae-like Faustovirus in biting midges, but also in a pool of $O$. sonrai soft ticks and in Boophilus sp., R. evertsi, and Amblyomma sp. pools of hard ticks. Interestingly, O. sonrai soft ticks were collected in the dust contained in rodents' nests and were not engorged, whereas hard ticks were collected directly from livestock and were engorged. Additionally, nearly $40 \%$ of the rodents tested were Faustoviruspositive, suggesting that $O$. sonrai soft ticks could be a possible vector for Faustovirus, and rodents could be a putative reservoir since no symptoms were observed on the captured rodents and high loads of Faustovirus were detected in their kidneys and urine, resulting in possible excretion of the virus in the environment. The detection of Faustovirus in Boophilus sp., $R$. evertsi, and Amblyomma sp. hard ticks could reflect the blood 
meal of the ticks and the viral persistence of the virus or the viral DNA within the arthropod, as previously reported (de Carvalho Ferreira et al., 2014).

So far, Faustovirus has been only detected in sewage in Marseille, Dakar and in Lebanon and Saudi Arabia (Reteno et al., 2015). In this study, we report for the first time the detection and isolation of Faustovirus in adult biting midges, and the detection of high viral loads of Faustovirus in rodents and cattle. We also reported the detection of Faustovirus in febrile patients and healthy people. This work thus, highlights the need to investigate the role of arthropods and wild or domestic animals on the lifecycle of the Asfarviridae-like Faustovirus and, more globally, for the amoeba-infecting giant viruses.

\section{AUTHOR CONTRIBUTIONS}

ST, BL, OM, DR, CD designed the experiments. ST, SM, SA, PD, JBK, JB, PJ, CR performed the experiments. ST, MS, MA collected the samples. ST, SA, PD, JBK, JB, OM wrote the article. BL, OM, $\mathrm{DR}, \mathrm{CD}$ revised the article.

\section{FUNDING}

This work was conducted under the frame of the ANR-13-JSV60004 awarded to Christelle Desnues.

\section{REFERENCES}

Agbolade, O. M., Akinboye, D. O., Olateju, T. M., Ayanbiyi, O. A., Kuloyo, O. O., and Fenuga, O. O. (2006). Biting of anthropophilic Culicoides fulvithorax (Diptera: Ceratopogonidae), a vector of Mansonella perstans in Nigeria. Korean J. Parasitol. 44, 67-72. doi: 10.3347/kjp.2006.44.1.67

Bishop-Lilly, K. A., Turell, M. J., Willner, K. M., Butani, A., Nolan, N. M., Lentz, S. M., et al. (2010). Arbovirus detection in insect vectors by rapid, high-throughput pyrosequencing. PLoS Negl. Trop. Dis. 4:e878. doi: 10.1371/journal.pntd.0000878

Boratto, P., Albarnaz, J. D., Almeida, G. M., Botelho, L., Fontes, A. C., Costa, A. O., et al. (2015). Acanthamoeba polyphaga Mimivirus prevents amoebal encystment-mediating serine proteinase expression and circumvents cell encystment. J. Virol. 89, 2962-2965. doi: 10.1128/JVI.03177-14

Boughalmi, M., Pagnier, I., Aherfi, S., Colson, P., Raoult, D., and La Scola, B. (2013a). First isolation of a Marseillevirus in the Diptera Syrphidae Eristalis tenax. Intervirology 56, 386-394. doi: 10.1159/000354560

Boughalmi, M., Pagnier, I., Aherfi, S., Colson, P., Raoult, D., and La Scola, B. (2013b). First isolation of a giant virus from wild Hirudo medicinalis leech: Mimiviridae isolation in Hirudo medicinalis. Viruses 5, 2920-2930. doi: $10.3390 / \mathrm{v} 5122920$

Breitbart, M., and Rohwer, F. (2005). Method for discovering novel DNA viruses in blood using viral particle selection and shotgun sequencing. Biotechniques 39, 729-736. doi: 10.2144/000112019

Burrage, T. G. (2013). African swine fever virus infection in Ornithodoros ticks. Virus Res. 173, 131-139. doi: 10.1016/j.virusres.2012.10.010

Chandler, J. A., Liu, R. M., and Bennett, S. N. (2015). RNA shotgun metagenomic sequencing of northern California (USA) mosquitoes uncovers viruses, bacteria, and fungi. Front. Microbiol. 6:185. doi: 10.3389/fmicb.2015. 00185

Chandler, J. A., Thongsripong, P., Green, A., Kittayapong, P., Wilcox, B. A., Schroth, G. P., et al. (2014). Metagenomic shotgun sequencing of a Bunyavirus in wild-caught Aedes aegypti from Thailand informs the evolutionary and genomic history of the Phleboviruses. Virology 464-465, 312-319. doi: 10.1016/j.virol.2014.06.036

\section{ACKNOWLEDGMENTS}

The authors would like to thank Samia Benamar for providing Faustovirus genome sequences, Ti Thien Nguyen and Noémie Labas for their help in preparing the Illumina libraries, Dr. Nicolás Rascovan for his critical comments and advice on the project, Jean-Michel Bérenger for his help in the morphological identification of ticks, Dr. Georges Diatta for the collection of soft ticks and the veterinarian Babacar Ndao for his help in animal sampling on the field.

\section{SUPPLEMENTARY MATERIAL}

The Supplementary Material for this article can be found online at: http://journal.frontiersin.org/article/10.3389/fmicb. 2015.01406

\section{Supplemental Figure 1 | Electrophoresis of PCR targeting the Faustovirus} capsid conducted on biting midges viromes.

Supplemental Figure 2 | Phylogenetic reconstruction of Faustovirus detected in biting midges viromes based on the (A) nucleotide sequence of the DNA topoisomerase small sub-unit (substitution model: HKY) (B) nucleotide sequence of the putative helicase C962R (substitution model: HKY).

Colson, P., de Lamballerie, X., Fournous, G., Raoult, D. (2012). Reclassification of giant viruses composing a fourth domain of life in the new order Megavirales. Intervirology 55, 321-332. doi: 10.1159/000336562

Colson, P., de Lamballerie, X., Yutin, N., Asgari, S., Bigot, Y., Bideshi, D. K., et al. (2013). "Megavirales," a proposed new order for eukaryotic nucleocytoplasmic large DNA viruses. Arch. Virol. 158, 2517-2521. doi: 10.1007/s00705-0131768-6

Coşkun, K. A., Ozçelik, S., Tutar, L., Eladi, N., and Tutar, Y. (2013). Isolation and identification of free-living amoebae from tap water in Sivas, Turkey. Biomed. Res. Int. 2013:675145. doi: 10.1155/2013/675145

de Carvalho Ferreira, H. C., Tudela Zúquete, S., Wijnveld, M., Weesendorp, E., Jongejan, F., Stegeman, A., et al. (2014). No evidence of African swine fever virus replication in hard ticks. Ticks Tick Borne Dis. 5, 582-589. doi: 10.1016/j.ttbdis.2013.12.012

Dinsdale, E. A., Edwards, R. A., Hall, D., Angly, F., Breitbart, M., Brulc, J. M., et al. (2008). Functional metagenomic profiling of nine biomes. Nature 452, 629-632. doi: 10.1038 /nature06810

Dornas, F. P., Rodrigues, F. P., Boratto, P. V., Silva, L. C., Ferreira, P. C., Bonjardim, C. A., et al. (2014). Mimivirus circulation among wild and domestic mammals, Amazon Region, Brazil. Emerg. Infect. Dis. 20, 469-472. doi: 10.3201/eid2003.131050

Edgar, R. C. (2004). MUSCLE: multiple sequence alignment with high accuracy and high throughput. Nucleic Acids Res. 32, 1792-1797. doi: 10.1093/nar/gkh340

Evans, J. D., and Schwarz, R. S. (2011). Bees brought to their knees: microbes affecting honey bee health. Trends Microbiol. 19, 614-620. doi: 10.1016/j.tim.2011.09.003

Greub, G., and Raoult, D. (2004). Microorganisms resistant to free-living amoebae. Clin. Microbiol. Rev. 17, 413-433. doi: 10.1128/CMR.17.2.413-433.2004

Harrup, L. E., Purse, B. V., Golding, N., Mellor, P. S., and Carpenter, S. (2013). Larval development and emergence sites of farm-associated Culicoides in the United Kingdom. Med. Vet. Entomol. 27, 441-449. doi: 10.1111/mve.12006

Hubálek, Z., Rudolf, I., and Nowotny, N. (2014). Arboviruses pathogenic for domestic and wild animals. Adv. Virus Res. 89, 201-275. doi: 10.1016/B9780-12-800172-1.00005-7 
Khan, M. M., Pyle, B. H., and Camper, A. K. (2010). Specific and rapid enumeration of viable but nonculturable and viable-culturable gram-negative bacteria by using flow cytometry. Appl. Environ. Microbiol. 76, 5088-5096. doi: 10.1128/AEM.02932-09

Legendre, M., Bartoli, J., Shmakova, L., Jeudy, S., Labedie, K., Adrait, A., et al. (2014). Thirty-thousand-year-old distant relative of giant icosahedral DNA viruses with a pandoravirus morphology. Proc. Natl. Acad. Sci. U.S.A. 111, 4274-4279. doi: 10.1073/pnas.1320670111

Mellor, P. S., Boorman, J., and Baylis, M. (2000). Culicoides biting midges: their role as arbovirus vectors. Annu. Rev. Entomol. 45, 307-340. doi: 10.1146/annurev.ento.45.1.307

Nakao, R., Abe, T., Nijhof, A. M., Yamamoto, S., Jongejan, F., Ikemura, T., et al. (2013). A novel approach, based on BLSOMs (Batch Learning SelfOrganizing Maps), to the microbiome analysis of ticks. ISME J. 7, 1003-1015. doi: 10.1038/ismej.2012.171

Nazar, M., Haghighi, A., Taghipour, N., Ortega-Rivas, A., Tahvildar-Biderouni, F., Nazemalhosseini Mojarad, E., et al. (2012). Molecular identification of Hartmannella vermiformis and Vannella persistens from man-made recreational water environments, Tehran, Iran. Parasitol. Res. 111, 835-839. doi: 10.1007/s00436-012-2906-x

Ng, T. F., Willner, D. L., Lim, Y. W., Schmieder, R., Chau, B., Nilsson, C., et al. (2011). Broad surveys of DNA viral diversity obtained through viral metagenomics of mosquitoes. PLoS ONE 6:e20579. doi: 10.1371/journal.pone.0020579

Niyyati, M., Rahimi, F., Lasejerdi, Z., and Rezaeian, M. (2014). Potentially pathogenic free-living amoebae in contact lenses of the asymptomatic contact lens wearers. Iran J. Parasitol. 9, 14-19.

Pagnier, I., Reteno, D. G., Saadi, H., Boughalmi, M., Gaia, M., Slimani, M., et al. (2013). A decade of improvements in Mimiviridae and Marseilleviridae isolation from amoeba. Intervirology 56, 354-363. doi: 10.1159/000354556

Philippe, N., Legendre, M., Doutre, G., Couté, Y., Poirot, O., Lescot, M., et al. (2013). Pandoraviruses: amoeba viruses with genomes up to $2.5 \mathrm{Mb}$ reaching that of parasitic eukaryotes. Science 341, 281-286. doi: 10.1126/science.1239181

Reteno, D. G., Benamar, S., Bou Khalil, J., Andreani, J., Armstrong, N., Klose, T., et al. (2015). Faustovirus, an asfarvirus-related new lineage of giant viruses infecting amoebae. J. Virol. 89, 6585-6594. doi: 10.1128/JVI.00115-15

Rho, M., Tang, H., and Ye, Y. (2010). FragGeneScan: predicting genes in short and error-prone reads. Nucleic Acids Res. 38, e191. doi: 10.1093/nar/gkq747

Rosario, K., Capobianco, H., Ng, T. F., Breitbart, M., and Polston, J. E. (2014). RNA viral metagenome of whiteflies leads to the discovery and characterization of a whitefly-transmitted carlavirus in North America. PLOS ONE 9:e86748. doi: 10.1371/journal.pone.0086748

Sambou, M., Aubadie-Ladrix, M., Fenollar, F., Fall, B., Bassene, H., Almeras, L., et al. (2015). Comparison of matrix-assisted laser desorption ionization-time of flight mass spectrometry and molecular biology techniques for identification of Culicoides (Diptera: Ceratopogonidae) biting midges in Senegal. J. Clin. Microbiol. 53, 410-418. doi: 10.1128/JCM.01855-14

Sikes, R. S., and Gannon, W. L. (2011). Guidelines of the American Society of Mammalogists for the use of wild mammals in research. J. Mammal. 92, 235-253. doi: 10.1644/10-MAMM-F-355.1

Sime-Ngando, T., Mignot, J. P., Amblard, C., Bourdier, G., Desvilettes, C., QuiblierLloberas, C., et al. (1996). Characterization of planktonic virus-like particles in a French mountain lake: methodological aspects and preliminary results. Ann. Limnol. 32, 259-263. doi: 10.1051/limn/1996025

Slama, D., Haouas, N., Remadi, L., Mezhoud, H., Babba, H., and Chaker, E. (2014). First detection of Leishmania infantum (Kinetoplastida: Trypanosomatidae) in Culicoides spp. (Diptera: Ceratopogonidae). Parasit. Vectors 7:51. doi: 10.1186/1756-3305-7-51

Slimani, M., Pagnier, I., Boughalmi, M., Raoult, D., and La Scola, B. (2013). Alcohol disinfection procedure for isolating giant viruses from contaminated samples. Invervirology 56, 434-440. doi: 10.1159/000354566

Sokhna, C., Mediannikov, O., Fenollar, F., Bassene, H., Diatta, G., Tall, A., et al. (2013). Point-of-care laboratory of pathogen diagnosis in rural Senegal. PLoS Negl. Trop. Dis. 7:e1999. doi: 10.1371/journal.pntd.0001999

Tamura, K., Stecher, G., Peterson, D., Filipski, A., and Kumar, S. (2013). Molecular evolutionary genetics analysis version 6.0. Mol. Biol. Evol. 30, 2725-2729. doi: $10.1093 / \mathrm{molbev} / \mathrm{mst} 197$

Temmam, S., Monteil-Bouchard, S., Robert, C., Pascalis, H., Michelle, C., Jardot, P., et al. (2015). Host-associated metagenomics: a guide to generating infectious RNA viromes. PLoS ONE 10:e0139810. doi: 10.1371/journal.pone.0139810

Warnecke, F., Luginbühl, P., Ivanova, N., Ghassemian, M., Richardson, T. H., Stege, J. T., et al. (2007). Metagenomic and functional analysis of hindgut microbiota of a wood-feeding higher termite. Nature 450, 560-565. doi: 10.1038 /nature06269

Yoosuf, N., Pagnier, I., Fournous, G., Robert, C., La Scola, B., and Raoult, D. (2014). Complete genome sequence of Courdo11 virus, a member of the family Mimiviridae. Virus Genes 48, 218-223. doi: 10.1007/s11262-013-1016-x

Conflict of Interest Statement: The authors declare that the research was conducted in the absence of any commercial or financial relationships that could be construed as a potential conflict of interest.

Copyright (c) 2015 Temmam, Monteil-Bouchard, Sambou, Aubadie-Ladrix, Azza Decloquement, Bou Khalil, Baudoin, Jardot, Robert, La Scola, Mediannikov, Raoult and Desnues. This is an open-access article distributed under the terms of the Creative Commons Attribution License (CC BY). The use, distribution or reproduction in other forums is permitted, provided the original author (s) or licensor are credited and that the original publication in this journal is cited, in accordance with accepted academic practice. No use, distribution or reproduction is permitted which does not comply with these terms. 